AGRARIS: Journal of Agribusiness and Rural Develpoment Research

Vol. 4 No. 2 Juli-Desember 2018
Adi Suyatno*, Imelda, Komariyati

Program Studi Agribisnis, Fakultas Pertanian, Universitas Tanjungpura, Pontianak

*e-mail korespondensi: adi01istiqomah@gmail.com

\section{Pengaruh Penggunaan Traktor Terhadap Pendapatan dan Penggunaan Tenaga Kerja pada Usahatani Padi di Kabupaten Sambas}

\author{
The Effect of Tractor Utilization on Revenue and \\ Use of Labor on Rice Farming in Sambas Regency
}

DOI: http://dx.doi.org/10.18196/agr.4264

\begin{abstract}
Development of agriculture mechanization in Sambas Regency is needed in order to support the increased of rice production. Technically, agricultural mechanization is expected to increase the productivity of the land and, economically, it is expected to increase farmers' income. The purpose of this research is to analyze the effect of tractor usage on income and availability of labor in rice farming. This research was conducted in Sambas Regency, using survey method. The results showed that the use of tractors for soil processing significantly increased the productivity and income of rice farming. The use of tractors on soil treatment has increased productivity by $667 \mathrm{~kg} / \mathrm{ha}$. The use of tractors on land treatment also increased revenues by Rp.2.843.400, Iha, although raising the cost. In-house labor and farming families are available for soil cultivation, but farmers generally prefer to use the tractors for soil treatment.
\end{abstract}

The use of tractors has reduced the use of labor, thus accelerating land preparation and planting activities. Farmers who do not use tractors because of environmental factors farming, namely the unavailability of irrigation.

Keywords: Income, Labor, Mechanization, Production.

\section{INTISARI}

Pengembangan mekanisasi pertanian di Kabupaten Sambas perlu dilakukan untuk dapat mendukung peningkatan produksi padi. Secara teknis mekanisasi pertanian diharapkan dapat meningkatkan produktivitas lahan dan secara ekonomi diharapkan dapat meningkatkan pendapatan petani.Penelitian ini bertujuan untuk menganalisis pengaruh penggunaan traktor terhadap pendapatan dan penggunaan tenaga kerja pada usahatani padi. Penelitian dilakukan di Kabupaten Sambas, dengan metode survey. Hasil penelitian menunjukkan penggunaan traktor untuk pengolahan tanah dapat meningkatkan produktivitas dan pendapatan usahatani padi. Penggunaan traktor pada pengolahan tanah telah meningkatkan produktivitas sebesar $667 \mathrm{~kg} / \mathrm{ha}$. Penggunaan traktor pada pengolahan tanah juga telah meningkatkan pendapatan sebesar Rp.2.843.400,-/ha, walaupun meningkatkan biaya. Tenaga kerja dalam dan luar keluarga petani tersedia untuk pengolahan tanah, namun umumnya petani memilih menggunakan traktor untuk pengolahan tanah. Penggunaan traktor telah mengurangi penggunaan tenaga kerja sehingga dapat mempercepat kegiatan persiapan lahan dan penanaman. Petani yang tidak menggunakan traktor karena faktor lingkungan usahatani, yaitu tidak tersedianya pengairan yang memadai.

Kata kunci: Mekanisasi, Pendapatan, Produksi, Tenaga Kerja.

\section{PENDAHULUAN}

Kebutuhan pangan masyarakat terutama beraspada tingkat nasional dan regional terus meningkat seiring dengan peningkatan jumlah penduduk setiap tahun. Indonesia pernah mencapai swasembada beras pada tahun 1984 tetapi hanya mampu bertahan sampai pada tahun 1993 dan setelah itu Indonesia mulai melakukan impor beras dari dari negara lain. Untuk mewujudkan ketahanan pangan dan mencapai kembali swasembada beras, dibutuhkan 

peningkatan produksi beras melalui usaha intensifikasi (peningkatan produktivitas lahan) dan ekstensifikasi (perluasan areal pertanaman padi) di sentra-sentra produksi (Suwarno, 2010).

Provinsi Kalimantan Barat memiliki potensi sumber daya lahan yang cukup tinggi untuk pengembangan usaha pertanian, terutama tanaman padi sawah. Data BPS mencatat luas lahan sawah tahun 2016 di Provinsi Kalimantan Barat sebesar 530.578 ha yang terdiri dari lahan sawah irigasi sebesar 105.608 ha dan lahan sawah non irigasi sebesar 424.970 ha.Kabupaten Sambas merupakan salah satu daerah sentra produksi pertanian di Kalimantan Barat, terutama untuk pengembangan tanaman pangan seperti padi sawah. Luas lahan sawah di Kabupaten Sambas mencapai 69.535 ha atau 10,87 \% dariluas Kabupaten Sambas yaitu 639.470 ha. Luas panen padi sawah di Kabupaten Sambas Tahun 2015 mencapai 101.266 ha, dengan jumlah produksi 286.159 ton (BPS, 2017).

Penduduk Kabupaten Sambas berjumlah 526.367 jiwa dengan kepadatan penduduk sebesar 82 jiwa/ $\mathrm{km} 2$ dan laju pertumbuhan penduduk tahun 2010-2016 sebesar 0,94 \% dan jumlah petani 137.172 orang. Kepadatan penduduk Kabupaten Sambas yang relatif rendah dan masih rendahnya produktivitas padi sawah, diduga merupakan faktor utama penyebab masih luasnya lahan pertanian yang belum dimanfaatkan dan perlu adanya peningkatan produktivitas. Penerapan mekanisasi pertanian melalui penggunaan alat dan mesin pertanian dapat menjadi solusi permasalahan tersebut melalui upaya intensifikasi (peningkatan produktivitas lahan) dan ekstensifikasi (perluasan areal tanam), serta menurunkan kehilangan hasil panen. Penggunaan alat mesin pertanian juga dapat meningkatkan kualitas hasil produksi tanaman padi, yaitu meningkatkan rendemen beras, penurunan kadar beras patah, meningkatkan tingkat keputihan beras, dan menurunkan kandungan kotoran dalam beras.

Pemerintah daerah Kalimantan Barat, khususnya Dinas Pertanian Tanaman Pangan dan Hortikultura, telah melakukan pengembangan sektor pertanian dengan menggunakan alat dan mesin pertanian yang difokuskan untuk mendukung pertanaman padi dan palawija. Di Kalimantan Barat, mekanisasi pertanian mulai dikembangkan oleh pemerintah pada Tahun 1998 melalui program Usaha Pelayanan Jasa Alsintan (UPJA), yang meliputi traktor tangan, pompa irigasi, power thresher, penggiling padi dan alat mesin pengering, dan setiap tahun terjadi penambahan alsintan, baik dalam jumlah maupun jenis alsintan. Adanya keberadaan kelembagaan Usaha Pelayanan Jasa Alsintan (UPJA) menjadi penting terutama dalam hal penyediaan jasa alsintan tepat waktu dan dengan biaya yang terjangkau oleh petani. Pada tahun-tahun belakangan ini di sebagian daerah, keberadaan alsintan juga berasal dari bantuan dana aspirasi anggota DPRD, baik DPRD tingkat I maupun tingkat II.

TABEL 1. DATA JENIS DAN JUMLAH ALSINTAN DI KALIMANTAN BARAT DAN KABUPATEN SAMBAS

\begin{tabular}{clrc}
\hline No. & Jenis Alsintan & \multicolumn{2}{c}{ Jumlah Alsintan } \\
\cline { 3 - 4 } & & $\begin{array}{c}\text { Kalimantan } \\
\text { Barat }\end{array}$ & $\begin{array}{c}\text { Kabupaten } \\
\text { Sambas }\end{array}$ \\
\hline 1. & Hand Tractor & 3.438 & 33 \\
2. & Power Thresher & 1.221 & 22 \\
3. & Reaper & 11 & - \\
4. & Transplanter & 17 & - \\
5. & Pady Mower & 8 & - \\
6. & Dryer & 8 & - \\
7. & Mesin Penggerak & 9 & - \\
8. & Seed Cleaner & 12 & - \\
9. & Cultivator & 45 & - \\
10. & Pompa Air & 708 & 85 \\
11. & RMU & 490 & 6 \\
12. & Corn Seller & 98 & - \\
13. & Combine Harverster & 8 & - \\
\hline
\end{tabular}

Sumber: (Dinas Pertanian Tanaman Pangan dan Hortikultura, 2016)

Ketersediaan jenis dan jumlah alsintan di Kabupaten Sambas masih sangat minim dan perlu penambahan alsintan, sebagaimana dapat dilihat pada Tabel 1, mengingat jumlah luas lahan sawah di Kabupaten Sambas yang sangat luas yaitu 57.114 ha atau sebesar 29,09 \% dari luas lahan sawah Kalimantan Barat. Salah satu jenis alsintan yang sangat penting peranannya dan banyak digunakan pada usahatani padi di Kabupaten Sambas adalah traktor. Alsintan di Kalimantan Barat khususnya hand tractor berjumlah 3.438 unit, sedangkan jumlah hand tractor di Kabupaten Sambas yaitu 33 unit (Dinas Pertanian Tanaman Pangan dan Hortikultura, 2016). Jumlah hand tractor di Kabupaten Sambas yang masih sedikit mengindikasikan bahwa adopsi petani 
terhadap teknologi mesin pertanian berupa traktor yang rendah dan pengembangan mekanisasi pertanian yang berjalan lambat di wilayah tersebut. Jika dibandingkan antara luas lahan sawah dengan ketersediaan hand tractor di Kabupaten Sambas tersebut, maka masih diperlukan tambahan hand tractor yang cukup banyak, yaitu sekitar 3.424 unit.

Keunggulan penggunaan traktor yaitu dapat mensubstitusi penggunaan tenaga kerja yang semakin mahal dan langka di daerah pedesaan Kalimantan Barat, terutama untuk kegiatan persiapan lahan usahatani padi. Selain itu, traktor adalah alat pertanian yang digunakan untuk kegiatan persiapan lahan, yang memiliki proporsi kebutuhan terhadap tenaga kerja relatif tinggi, sehingga biaya yang diperlukan juga relatif tinggi. Efisiensi biaya pada kegiatan persiapan lahan akan memberikan pengaruh pada peningkatan pendapatan usahatani padi. Traktor juga dapat mempercepat kegiatan persiapan lahan, sehingga memungkinkan petani untuk melakukan penanaman tepat waktu pada musim tanam. Penelitian Takele \& Selassie (2018) menyatakan bahwa penggunaan traktor di Negara Ethiopia meningkat seiring dengan berkurangnya kepemilikan ternak yang bisa digunakan untuk membajak sawah.

Penelitian pengembangan mekanisasi pertanian di Kabupaten Sambas perlu dilakukan untuk dapat mendukung peningkatan produksi padi. Secara teknis mekanisasi pertanian diharapkan dapat meningkatkan produktivitas lahan dan kualitas beras, secara sosial diharapkan dapat memberikan dampak terhadap semangat kerja petani, dan secara ekonomi diharapkan dapat meningkatkan pendapatan petani dan pertumbuhan perekonomian di sektor lain. Tujuan penelitian ini adalah untuk menganalisis pengaruh penggunaan traktor terhadap pendapatan dan penggunaan tenaga kerja pada usahatani padi.

\section{METODE PENELITIAN}

Penelitian ini dilakukan dengan metode survey yaitu penelitian yang mempelajari data dari sampel yang mewakili populasi untuk menjelaskan kondisi-kondisi relatif, distribusi dan hubungan antar variabel (Sugiyono, 2012). Usahatani padi dalam penelitian ini adalah usahatani padi sawah tadah hujan. Sampel lokasi penelitian dipilih secara sengaja, yaitu di Kecamatan Tebas dan Kecamatan Semparuk, dengan pertimbangan dua lokasi tersebut memiliki karakteristik yang berbeda, yaitu di Kecamatan Tebas, pengolahan tanahnya dilakukan dengan tenaga manusia, sedangkan di Kecamatan Semparuk pengolahan tanahnya menggunakan traktor. Sampel penelitian berjumlah 60 petani dengan perincian 30 petani mewakili Kecamatan Tebas dan 30 petani mewakili Kecamatan Semparuk. Pengumpulan data bersumber dari data primer dan data sekunder. Data primer berupa hasil wawancara dengan petani responden meliputi karakteristik petani responden, biaya produksi, hasil produksi, harga jual dan penggunaan tenaga kerja. Data sekunder berasal dari arsip dan laporan BPS serta Dinas Pertanian Tanaman Pangan dan Hortikultura. Penelitian ini dilakukan pada dua lokasi kecamatan yang berdekatan, sehingga dapat diasumsikan menggunakan varietas padi dan teknik budidaya yang sama. Penelitian dilakukan pada musim tanam penghujan (rendengan) tahun 2017.

Pendapatan usahatani $(\mathrm{Rp})$ merupakan total penerimaan usahatani $(\mathrm{Rp})$ dikurangi TC adalah biaya eksplisit $(\mathrm{Rp})$, total penerimaan usahatani $(\mathrm{Rp})$ adalah harga padi $(\mathrm{Rp} / \mathrm{kg})$ dikalikan produksi padi $(\mathrm{kg})$, sedangkan biaya eksplisit ( $\mathrm{Rp}$ ) adalah penjumlah biaya variabel (Rp) dan biaya tetap (Rp) (Irianto, 2009): Untuk melihat pengaruh penggunaan traktor terhadap produktivitas dan pendapatan usahatani padi menggunakan uji beda terhadap produktivitas dan pendapatan usahatani padi, dari kelompok petani yang menggunakan traktor dan kelompok petani yang menggunakan tenaga kerja manusia dalam pengolahan tanah. Produktivitas dan pendapatan usahatani padi dibandingkan dengan menggunakan independent sample t-test (Irianto, 2009).

Untuk mengetahui pengaruh penggunaan traktor terhadap penggunaan tenaga kerja, dilakukan analisis secara deskriptif, dengan melihat perbandingan penggunaan tenaga kerja pada usahatani padi yang menggunakan traktor dan yang menggunakan tenaga manusia. 


\section{HASIL DAN PEMBAHASAN}

\section{KERAGAAN USAHATANI PADI}

Kabupaten Sambas memiliki tiga komoditas utama yang berpotensi untuk dikembangkan yaitu padi, palawija dan hortikultura. Khusus komoditas padi, ketersediaan luas lahan potensial sebesar 26.723 ha. Luas yang sudah digunakan sebesar 22.000 ha, sehingga tersisa 3.790 ha lahan untuk pengembangan padi (BPS, 2016). dua lokasi sampel, yaitu di Kecamatan Tebas dan Kecamatan Semparuk, luas panen padi meningkat dari tahun ke tahun.

TABEL 2. LUAS PANEN PADI DI KECAMATAN TEBAS DAN KECAMATAN SEMPARUK, KABUPATEN SAMBAS

\begin{tabular}{ccc}
\hline \multirow{2}{*}{ Tahun } & \multicolumn{2}{c}{ Luas Panen (ha) } \\
\cline { 2 - 3 } & Kecamatan Tebas & Kecamatan Semparuk \\
\hline 2012 & 6.090 & 3.820 \\
2013 & 6.110 & 3.930 \\
2014 & 6.220 & 3.955 \\
2015 & 6.730 & 4.180 \\
2016 & 6.835 & 4.350 \\
\hline
\end{tabular}

Sumber: (BPS, 2017)

Tabel 2 menunjukkan bahwa rata-rata luas panen di Kecamatan Tebas lebih tinggi dibandingkan dengan di Kecamatan Semparuk. Namun produktivitas padi di Kecamatan Tebas sebesar 2.260 $\mathrm{kg} / \mathrm{ha}$ dan lebih rendah dibandingkan dengan ratarata produktivitas di Kecamatan Semparuk yaitu sebesar $2.970 \mathrm{~kg} / \mathrm{ha}$. Perbedaan produktivitas ini terjadi karena beberapa sebab salah satunya karena hambatan teknologi. Hambatan teknologi bisa terjadi karena belum optimalnya penggunaan input produksi dan minimnya adopsi teknologi budidaya seperti pengolahan tanah untuk kegiatan penanaman padi.

Usahatani padi di wilayah Kecamatan Tebas dan Kecamatan Semparuk memiliki karakteristik yang berbeda. Budidaya tanaman padi di Kecamatan Tebas sebagian besar dilakukan dengan pengolahan tanah tanpa traktor, yaitu pengolahan tanah dengan tenaga kerja manusia. Sebagian besar lahan merupakan sawah tadah hujan dengan kondisi ketersediaan air yang kurang. Hal tersebut mengakibatkan penggunaan traktor untuk pengolahan tanah jarang dilakukan. Budidaya tanaman padi di Kecamatan Semparuk sebagian besar menggunakan traktor untuk kegiatan pengolahan tanah. Pengolahan tanah dilakukan dengan cara dibajak. Awalnya rumput yang ada di lahan disemprot menggunakan herbisida. Setelah satu minggu lahan dibajak dengan traktor dan diratakan. Saat ketersediaan air di lahan kurang, terutama di musim kemarau, petani yang lahannya berdekatan dengan sumber air tetap melakukan pembajakan tanah dengan menyuplai air ke lahan menggunakan mesin pompa air.

\section{PENGARUH PENGGUNAAN TRAKTOR TERHADAP PRODUKTIVITAS USAHATANI PADI}

Perbedaan cara dalam pengolahan tanah di Kecamatan Tebas dan Kecamatan Semparuk, dimana lokasi pertamatidak menggunakan traktor dan lokasi kedua menggunakan traktorberpengaruh terhadap produktivitas usahatani padi.

\begin{tabular}{lrr}
\multicolumn{3}{c}{$\begin{array}{c}\text { TABEL 3. PRODUKTIVITAS DAN PENGGUNAAN INPUT } \\
\text { USAHATANI PADI DI KECAMATAN TEBAS DAN }\end{array}$} \\
\multicolumn{1}{c}{ KECAMATAN SEMPARUK KABUPATEN SAMBAS } \\
\hline \multicolumn{1}{c}{ Input } & \multicolumn{2}{c}{ Kecamatan (Penggunaan Alsintan) } \\
\cline { 2 - 3 } & Kecamatan Tebas & $\begin{array}{r}\text { Kecamatan } \\
\text { Semparuk }\end{array}$ \\
\hline $\begin{array}{l}\text { Produktivitas } \\
\text { (kg/ha) }\end{array}$ & $2.248,00$ & $2.925,00$ \\
Produksi (kg) & $1.349,00$ & $2.925,00$ \\
Lahan (ha) & 0,60 & 1,00 \\
Pupuk (kg/ha) & & \\
$\quad$ Urea & 61,00 & 87,00 \\
$\quad$ NPK & 141,00 & 136,00 \\
Benih (kg/ha) & 20,00 & 34,0 \\
Tenaga Kerja & 52,00 & 44,00 \\
(HOK/ha) & & \\
Herbisida (It/ha) & 2,70 & 2,70 \\
Insektisida (It/ha) & 0,47 & 0,44
\end{tabular}

Sumber :Analisis data primer, 2017

Tabel 3 menunjukkan penggunaan input benih, pupuk dan tenaga kerja yang hampir sama pada dua lokasi, namun memiliki produktivitas yang berbeda. Hasil uji t (Tabel 4) menunjukkan adanya perbedaan nyata antara produktivitas padi di Kecamatan Tebas dengan produktivitas padi di Kecamatan Semparuk.

TABEL 4. UJI BEDA TERHADAP PRODUKTIVITAS DAN PENDAPATAN USAHATANI PADI DI KECAMATAN TEBAS DAN KECAMATAN SEMPARUK KABUPATEN SAMBAS

\begin{tabular}{|c|c|c|c|}
\hline Variabel & $t$ & Sig & Keterangan \\
\hline Produksi & $5,148^{*}$ & 0,000 & Signifikan \\
\hline Pendapatan & $3,484^{*}$ & 0,000 & Signifikan \\
\hline
\end{tabular}

Sumber : Analisis data primer, 2017 
Perbedaan produktivitas terjadi karena adanya penggunaan traktor untuk pengolahan tanah di Kecamatan Semparuk. Penerapan sistem pengolahan tanah yang lebih baik akan meningkatkan produksi berbagai jenis tanaman (Gribaldi, 2015; Prasetyo, Nugroho, \& Moenandir, 2014).

\section{PENGARUH PENGGUNAAN TRAKTOR TERHADAP PENDAPATAN USAHATANI PADI}

Untuk melihat pengaruh penggunaan traktor terhadap pendapatan usahatani padi perlu dilihat terlebih dahulu perbedaan penerimaan dan biaya usahataninya. Pada aspek penerimaan usahatani, diantara dua lokasi perbedaan produktivitas, dengan asumsi tidak ada perbedaan harga di dua lokasi tersebut karena tempatnya yang berdekatan pada satu kawasan. Sedangkan pada aspek biaya, perbedaan biaya diantara dua lokasi disebabkan adanya biaya sewa traktor di Kecamatan Semparuk. Uji t terhadap pendapatan (Tabel 4) pada dua keragaan usahatani padi tersebut menunjukkan terdapat perbedaan yang nyata antara pendapatan usahatani padi dengan melakukan pengolahan tanah dengan dan tanpa traktor. Pendapatan usahatani padi dengan pengolahan tanah menggunakan traktor lebih tinggi dibandingkan dengan menggunakan tenaga kerja manusia. Artinya terdapat pengaruh pengolahan tanah dengan menggunakan traktor terhadap pendapatan usahatani padi.

TABEL 5. ANALISIS BIAYA USAHATANI PADI DENGAN TRAKTOR DAN TANPA TRAKTOR

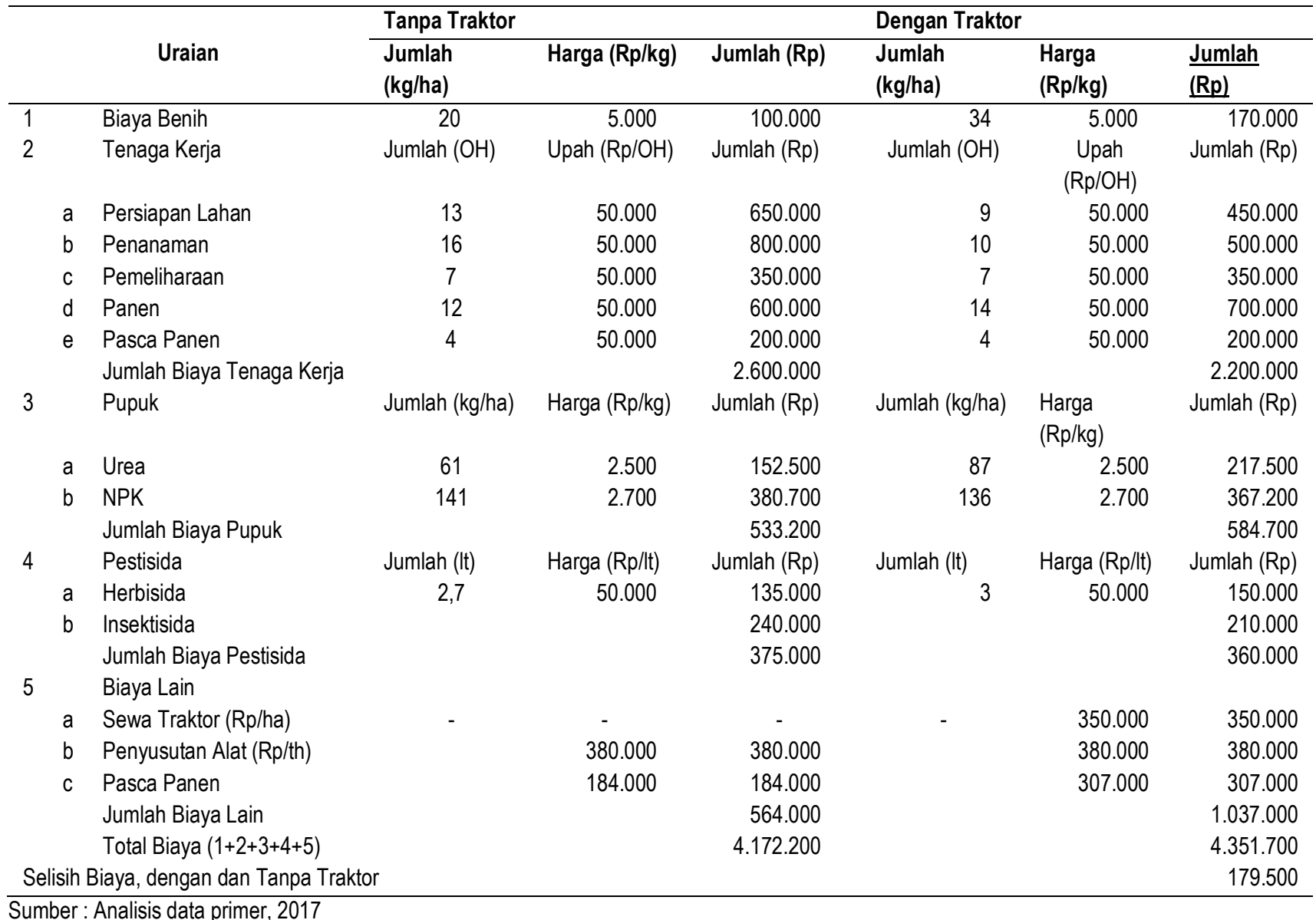

Pengolahan tanah dengan menggunakan traktor mengakibatkan kenaikan biaya sebesar Rp. 150.000,- perha, sebagai akibat dari substitusi tenaga kerja manusia oleh traktor. Sedangkan produksi yang dihasilkan perha berbeda dengan rata-rata sebesar 677 $\mathrm{kg} / \mathrm{ha}$, sehingga ditemukan perbedaan penerimaan sebesar Rp. 2.843.400,-. Akibatnya terjadi perbedaan pendapatan sebesar Rp.2.663.900,-/ha, atau petani 
mendapatkan tambahan pendapatan sebesar Rp.2.663.900,-/ha,. Penggunaan alsintan traktor menimbulkan kenaikan biaya, tetapi menguntungkan bagi petani. Penelitian Narayanamoorthy, Bhatttarai, Suresh, \& Alli (2014) juga menyatakan bahwa di India, penggunaan mekanisasi pertanian memang secara nyata telah meningkatkan biaya usahatani dan menurunkan jam kerja petani.

TABEL 6. ANALISIS PENDAPATAN USAHATANI PADI DENGAN TRAKTOR DAN TANPA TRAKTOR

\begin{tabular}{lrr}
\hline Uraian & Tanpa Traktor & Dengan Traktor \\
\hline Produksi (kg) & 2.248 & 2.925 \\
Harga (Rp/kg) & 4.200 & 4.200 \\
Penerimaan (Rp) & 9.441 .600 & 7.933 .300 \\
Selisih Penerimaan (Rp) & & 2.843 .400 \\
Pendapatan (Rp) & 5.269 .400 & 7.933 .300 \\
Selisih Pendapatan (Rp) & & 2.663 .900 \\
\hline Sumber : Analisis data primer, 2017 & &
\end{tabular}

Tabel 6 menunjukkan bahwa penggunaan traktor untuk pengolahan tanah telah mampu meningkatkan pendapatan bagi petani dan akan menjadi motivator bagi petani dalam menggunakan alsintan tersebut. Teknologi yang diterapkan harus memenuhi kriteria ekonomis dan menguntungkan bagi petani sehingga mendorong petani untuk mengadopsi teknologi tersebut. Keberanian petani dalam mencoba inovasi juga tergantung dengan kesukaan terhadap inovasi tersebut dan risiko yang harus dihadapi (Rahmawati \& Triyono, 2017). Proses adaptasi teknologi pertanian berupa penggunaan traktor berpeluang untuk meningkatkan hasil produksi pertanian (Sukartini \& Solihin, 2013). Pengembangan teknologi mekanisasi pertanian yang diselaraskan dengan kondisi fisik wilayah dan sosial ekonomi masyarakat akan meningkatkan perkembangan usaha pertanian (Umar, 2013).

Persoalan yang muncul adalah masih banyak petani di lokasi penelitian yang tidak menggunakan traktor untuk pengolahan tanah. Hal ini ternyata berkaitan dengan faktor lain berupa pengairan yang tidak tersedia di lokasi penelitian. Usahatani di Kecamatan Semparuk memilki pengairan yang bersumber dari aliran sungai dekat lokasi sawah, sedangkan pengairan di Kecamatan Tebas belum memadai. Perbedaan kondisi pengairan ini yang mengakibatkan tidak dilakukannya pengolahan tanah dengan traktor di wilayah Kecamatan Tebas. Selain berkaitan dengan hal teknis tersebut, penggunaan alsintan ini juga dipengaruhi oleh kondisi sosial ekonomi petani. Adopsi terhadap suatu teknologi dipengaruhi oleh beberapa faktor, yaitu tingkat pendidikan petani, luas lahan, umur, pengalaman bertani, jumlah tanggungan keluarga, pendapatan petani dan status pemilikan lahan (Soekartawi, 2002). Mekanisasi pertanian di negara India umumnya pertama kali diadopsi oleh petani-petani yang lebih mampu secara ekonomi (Singh, 2015). Faktor-faktor yang mempengaruhi petani dalam menerapkan mekanisasi pertanian yaitu pendapatan dan luas lahan (Rasouli, Sadighi, \& Minaei, 2009). Rangkuti (2009) menyatakan bahwa ada hubungan signifikan antara karakteristik petani, karakteristik usahatani, kecepatan adopsi teknologi dan jaringan komunikasi terhadap kecepatan adopsi teknologi penggunaan traktor olah tanah.

\section{PENGARUH PENGGUNAAN TRAKTOR TERHADAP PENGGUNAAN TENAGA KERJA PADA USAHATANI PADI}

Pengaruh penggunaan traktor untuk olah tanah berkaitan erat dengan penggunaan tenaga kerja usahatani. Umar (2013) menyatakan bahwa untuk mengatasi kelangkaan tenaga kerja, perlu masukan teknologi mekanisasi terutama pada kegiatan penyiapan lahan.

TABEL 7. PENGGUNAAN TENAGA KERJA USAHATANI PADI DENGAN TRAKTOR DAN TANPA TRAKTOR

\begin{tabular}{|c|c|c|c|c|c|c|}
\hline \multirow{2}{*}{$\begin{array}{l}\text { Uraian } \\
\text { Tenaga Kerja }\end{array}$} & \multicolumn{3}{|c|}{ Tanpa Traktor } & \multicolumn{3}{|c|}{ Dengan Traktor } \\
\hline & Jumlah (OH) & Upah (Rp/OH) & Jumlah (Rp) & Jumlah (OH) & Upah (Rp/OH) & Jumlah (Rp) \\
\hline Persiapan Lahan & 13 & 50.000 & 650.000 & 9 & 50.000 & 450.000 \\
\hline Penanaman & 16 & 50.000 & 800.000 & 10 & 50.000 & 500.000 \\
\hline Pemeliharaan & 7 & 50.000 & 350.000 & 7 & 50.000 & 350.000 \\
\hline Panen & 12 & 50.000 & 600.000 & 14 & 50.000 & 700.000 \\
\hline Pasca Panen & 4 & 50.000 & 200.000 & 4 & 50.000 & 200.000 \\
\hline Jumlah Biaya Tenaga Kerja & 52 & & 2.600 .000 & 44 & & 2.200 .000 \\
\hline
\end{tabular}


Tabel 7 menunjukkan bahwa penggunaan traktor telah mengurangi penggunaan tenaga kerja manusia terutama pada kegiatan pengolahan lahan dan mampu mengurangi biaya tenaga kerja keseluruhan sebebesar Rp 400.000,- perha. Walaupun penggunaan traktor meningkatkan biaya produksi secara keseluruhan (karena biaya sewa traktor yang lebih besar dari pada substitusi tenaga kerja), akan tetapi hal tersebut akan dikompensasi dengan meningkatnya pendapatan usahatani akibat peningkatan produktivitas dan penerimaan usahatani. Selain itu penggunaan traktor telah dapat menghemat penggunaan tenaga kerja yang dapat mempercepat kegiatan persiapan lahan, karena ketersediaan tenaga kerja yang semakin berkurang dan petani dapat melakukan penanaman tepat waktu pada musim tanam. Penerapan mekanisasi pertanian dalam jangka panjang akan mempengaruhi permintaan tenaga kerja manusia, meningkatkan efisiensi tenaga kerja manusia, serta meningkatkan kuantitas dan kualitas hasil produksi pertanian (Zhang, et al., 2018), (Fulin, Shengxue, \& Xiaoming, 2016), (Yinggang, et al., 2013).

Petani yang tidak menggunakan traktor lebih disebabkan karena faktor lingkungan usahatani yang tidak memungkinkan, yaitu tidak tersedianya pengairan yang memadai. Hal ini sesuai dengan yang dikemukakan oleh Djamhari (2009), bahwa pengoperasian alat dan mesin pertanian pada tingkat usahatani (baik dalam pelayanan jasa atau usaha kelompok maupun pribadi), harus sesuai dengan kondisi setempat. Sehingga apabila kondisi lingkungan setempat tidak sesuai untuk pengoperasian alat, maka peralatan mesin pertanian tersebut tidak dapat digunakan. Fadli, Daulay, \& Ichwan (2015) menyatakan bahwa sumber daya dan waktu pengolahan tanah pada lahan sawah dapat mempengaruhi kapasitas kinerja dan efisiensi tenaga mesin pertanian. Penerapan teknologi usahatani merupakan kebijakan yang harus terus ditingkatkan pada waktu yang tepat dan dengan biaya yang minimum, sehingga bisa meningkatkan produktivitas dan pendapatan usahatani (Owombo, Akinola,
Ayodele, \& Koledoye, 2012; Wijaya, 2017). Lebih lanjut lagi, Wahyuni \& Indraningsih (2003) menyatakan bahwa tidak mudah untuk mengintroduksi teknologi ke masyarakat. Perlu adanya sosialisasi program secara menyeluruh agar program tersebut akan berjalan dengan lancar dan berkelanjutan.

\section{KESIMPULAN}

Penggunaan alsintan berupa traktor meningkatkan produktivitas usahatani padi. Penggunaan traktor pada pengolahan tanah telah meningkatkan produktivitas rata-rata $667 \mathrm{~kg} / \mathrm{ha}$ sehingga meningkatkan penerimaan sebesar $\mathrm{Rp}$. 2.843.400,-. Penggunaan traktor pada pengolahan tanah telah meningkatkan pendapatan sebesar $\mathrm{Rp}$. 2.663.900,-/ha, walaupun menimbulkan kenaikan biaya, sebagai akibat dari substitusi tenaga kerja manusia oleh traktor.

Tenaga kerja dalam dan luar keluarga petani tersedia untuk pengolahan tanah, namun umumnya petani memilih menggunakan traktor untuk pengolahan tanah. Penggunaan traktor telah mengurangi penggunaan tenaga kerja. Penghematan penggunaan tenaga kerja dapat mempercepat kegiatan persiapan lahan, karena ketersediaan tenaga kerja yang semakin berkurang dan petani dapat melakukan penanaman tepat waktu pada musim tanam. Sebagian petani yang tidak menggunakan traktor lebih disebabkan karena faktor lingkungan usahatani yang tidak memungkinkan, yaitu tidak tersedianya pengairan yang memadai.

Saran yang dapat diberikan adalah perlu ada upaya pemerintah untuk menyediakan kondisi lingkungan usahatani padi, yang memungkinkan diterapkannya teknis budidaya penggunaan alsintan (traktor), berupa penyediaan pengairan untuk peningkatan produktivitas usahatani padi.

\section{UCAPAN TERIMA KASIH}

Penulis mengucapkan terimakasih kepada Direktorat Jenderal Pendidikan Tinggi Kementerian Riset Teknologi dan Pendidikan Tinggi yang telah 
memberikan pendanaan untuk Penelitian Produk Terapan (PPT) pada tahun 2017.

\section{DAFTAR PUSTAKA}

BPS. (2016). Kabupaten Sambas dalam Angka. Pontianak: BPS.

BPS. (2017). Provinsi Kalimantan Barat dalam Angka. Pontianak: BPS.

Djamhari, S. (2009). Kajian Penerapan Mekanisasi Pertanian di Lahan Rawa Lebak Desa Putak Muara Enim. Jakarta: Balai Pengkajian Teknologi Pertanian.

Fadli, A. R., Daulay, S. B., \& Ichwan, N. (2015). Kajian Efisiensi Biaya Produksi Terhadap Sumberdaya Pertanian untuk Pengolahan Tanah Pada Lahan Sawah di Desa Pelawi Utara Kecamatan Babalan Kabupaten Langkat. Jurnal Rekayasa Pangan, 3(3), 360-364. https://jurnal.usu.ac.id/index.php/jrpp/article/vi ew/Ahmad\%20Rizan\%20Fadli

Fulin, W., Shengxue, Z., \& Xiaoming, F. (2016). Improved Estimation Model and Empirical Analysis of Relationship Between Agricultural Mechanization Level and Labor Demand. International Journal Agricultural and Biological Engineering, 9(2), 48-53. 10.3965/j.ijabe.20160902.2188

Gribaldi. (2015). Peningkatan Pertumbuhan dan Produksi Jagung Manis Melalui Penerapan Sistem Pengolahan Tanah dan Pemberian Mulsa Pada Lahan. Jurnal Lahan Suboptimal, 4(2), 158-163. https://jlsuboptimal.unsri.ac.id/index.php/jlso/a rticle/view/163

Dinas Pertanian Tanaman Pangan dan Hortikultura. (2016). Laporan Tahunan 2016. Pontianak: Dinas Pertanian Tanaman Pangan dan Hortikultura.

Irianto. (2009). Statistik: Konsep Dasar dan Aplikasinya. Jakarta: Penerbit Kencana.

Narayanamoorthy, A., Bhatttarai, M., Suresh, R., \& Alli, P. (2014). Farm Mechanisation, MGNREGS and Labour Supply Nexus: A State-Wise Panel Data Analysis on Paddy and Wheat Crop. Indian Journal of Agricultural Economics, 69(3), 320335. http://purl.umn.edu/229836.

Owombo, Akinola, Ayodele, \& Koledoye. (2012). Economic Impact of Agricultural Mechanization Adoption: Evidence from Maize Farmers in Ondo State, Nigeria. Journal of Agriculture and Biodiversity Research, 1(2), 2532.

Prasetyo, R. A., Nugroho, A., \& Moenandir, J. (2014). Pengaruh Sistem Olah Tanah dan Berbagai Mulsa Organik Pada Pertumbuhan dan Hasil Tanaman Kedelai (Glycine Max L. Merr. Var.
Grobogan). Jurnal Produksi Tanaman, 1(6), 486-495.

http://protan.studentjournal.ub.ac.id/index.ph p/protan/article/view/63

Rahmawati, N., \& Triyono. (2017). Keberanian dalam Mengambil Keputusan dan Risiko oleh Petani Padi Organik di Kabupaten Bantul. Jurnal AGRARIS, 3(2), 128

137. http://dx.doi.org/10.18196/agr.3253

Rangkuti, P. (2009). Analisis Peran Jaringan Komunikasi Petani dalam Adopsi Inovasi Traktor Tangan di Kabupaten Cianjur, Jawa Barat. Jurnal Agro Ekonomi, 27(1), 45-60. http://dx.doi.org/10.21082/jae.v27n1.2009.45 $-60$

Rasouli, F., Sadighi, H., \& Minaei, S. (2009). Factors Affecting Agricultural Mechanization: A Case Study on Sunflower Seed Farms in Iran. Journal Agricultural Science and Technology, 11, 3948.http://jast-

old.modares.ac.ir/article $4388 . \mathrm{html}$

Singh, G. (2015). Mechanisation Development in India. Indian Journal of Agricultural Economics, 701), 64-82. http://purl.umn.edu/229967.

Soekartawi. (2002). Prinsip Dasar Ekonomi Pertanian Teori dan Aplikasi. Jakarta: PT. Raja Grafindo.

Sugiyono. (2012). Metode Penelitian Kuantitatif Kualitatif dan R\&D. Bandung: Penerbit Alfabeta.

Sukartini, N. M., \& Solihin, A. (2013). Respon Petani Terhadap Perkembangan Teknologi dan Perubahan Iklim: Studi Kasus Subak di Desa Gadungan, Tabanan, Bali. Jurnal Ekonomi Kuantitatif Terapan, 6(2), 128-139. https://ojs.unud.ac.id/index.php/jekt/article/vie w/7445.

Suwarno. (2010). Meningkatkan Produksi Padi Menuju Ketahanan Pangan yang Lestari. Jurnal Pangan, 19(3), 233-243. http://www.jurnalpangan.com/index.php/pang an/article/view/150.

Takele, A., \& Selassie, Y. G. (2018). Socio-Economic Analysis of Conditions for Adoption of Tractor Hiring Services Among Smallholder Farmers, Northwestern Ethiopia. Cogent Food and Agriculture, 4(1453978), 1-15. https://doi.org/10.1080/23311932.2018.1453 978

Umar, S. (2013). Pengelolaan Dan Pengembangan Alsintan untuk Mendukung Usahatani Padi Di Lahan Pasang Surut. Jurnal Teknologi Pertanian, 8(2), 37-48. https://jtpunmul.wordpress.com/publications2009-2013/vol-8-no-2/

Wahyuni, S., \& Indraningsih, K. (2003). Dinamika Program dan Kebijakan Peningkatan Produksi Padi. Forum Penelitian Agro Ekonomi, 21(2), 
AGRARIS: Journal of Agribusiness

and Rural Development Research

143-156.

http://dx.doi.org/10.21082/fae.v21n2.2003.14

3-156

Wijaya, O. (2017). Strategi Pengembangan Komoditas Pangan Unggulan dalam Menunjang Ketahanan Pangan Wilayah (Studi Kasus di Kabupaten Batang, Propinsi Jawa Tengah). Jurnal AGRARIS, 3(1), 48-56. http://dx.doi.org/10.18196/agr.3144

Yinggang, O., Wegener, M., Dantong, Y., Qingting, L., Dingke , Z., Meimei, W., et al. (2013). Mechanization Technology: The Key to Sugarcane Production in China. International Journal of Agricultural and Biological Engineering, 6(1), 1-27. https://www.ijabe.org/index.php/ijabe/article/vi ew/726

Zhang, M., Wang, Z., Luo, X., Zang, Y., Yang, W.,

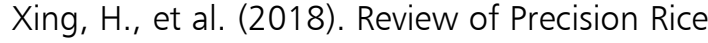
Hill Drop Drilling Technology and Machine for Paddy. International Journal Agricultural and Biological Engineering, 11(3), 1-11. 10.25165/j.ijabe.20181103.4249 